\title{
IS GOLD INVESTMENT A SAFE HAVEN OR A HEDGE FOR THE MALAYSIAN INFLATION?
}

\author{
M. S. M. Khair-Afham \\ University of London \\ Universiti Putra Malaysia \\ Siong-Hook Law* \\ Universiti Putra Malaysia \\ W. N. W. Azman-Saini \\ Universiti Putra Malaysia
}

\begin{abstract}
This study examines the long and short term abilities of gold to hedge against inflation in Malaysia during the period from 1971 to 2011 . The Johansen cointegration results reveal that there is a long term relationship between gold price and consumer price index. Using the Tsay's linearity test, the findings demonstrate the nonlinear relationship between gold return and inflation rate. Thus, the nonlinear threshold vector error-correction model (TVECM) analysis is employed to analyze the causal relationship and gold's hedging ability in short term. Gold is proven to be effective as a hedging tool against inflation, but effectiveness varies on different price momentums (based on threshold) and the time period. It is found that during high momentum regimes, gold return is able to hedge against inflation in Malaysia better than during low momentum regimes.
\end{abstract}

Keywords: Gold; Inflation; Hedging Ability; Asymmetric Causality; TVECM.

\section{INTRODUCTION}

Hedging against inflation was a popular debate among researchers as the inflation rate was significantly higher than the recent rate. People panicked as prices of goods kept on increasing at a high pace and academicians tried to come up with ideas of hedging against it. After numerous major financial crises, governments, policy makers and participants from private sectors attempted to stabilize the output and stripped off deflation by implementing liquidity operations. The effect of this liquidity operation was that it triggered the economic entities as inflation would be higher. Increasing inflation rates are risky and harmful to every participant in the economy. It resulted in inefficiencies in the market and firms would have problems in preparing their budgets or outlaying their long term planning. It also would affect firms in a way that will drag on productivity as firms

\footnotetext{
*Corresponding author: Department of Economics, Universiti Putra Malaysia, 43400 UPM Serdang, Selangor, MALAYSIA. Email: lawsh@upm.edu.my. Tel: +603-89467768
} 
have to shift capitals away from products or services as they now have to focus on losses from lower purchasing power.

Inflation also will result in uncertainty. When this happens, it will discourage investments and saving. The definition of the term 'hedging' is frequently misunderstood when discussing the preservement of the value of assets in a portfolio. Hedging against inflation is defined as the return of an asset correlating with inflation over time. In short, asset return follows the same trend as inflation. According to Bodie (1976), the return of any holdings that could outweigh the inflation rate is considered as a hedge against inflation. Bodie (1979) also argued that hedging is important for individuals who want to preserve the purchasing power institutional investors to reduce risks. Conventional literatures' view of gold is that it has a hedging ability against inflation. However, the conclusions of previous literatures are quite inconsistent as to whether or not gold is able to hedge against inflation, although most of the literatures suggest so.

For the last four decades, the inflation rate in Malaysia could be divided into two segments. The first segment is from 1971 until 1990 where the inflation rates were fluctuated in the higher range compared to 1991 until 2011. Even though the Malaysian inflation rates were considerably higher during the early 1970s, international standards have considered the rates as reasonably low during that period. A few years before that, Malaysia faced a single digit rate of inflation by only around $2 \%$. Malaysia's overall inflation rate has been constant at a moderately low level as shown in Figure 1. From 1990 to 2012 , the rate can be fluctuated around $1 \%$ to $5 \%$ even when the huge Asian financial crisis of 1997 until 1998 and the severe devaluation of the Malaysian ringgit in the same period, although there has been quite an increase in inflation rate during that period.

In the macroeconomics literature, there are numerous conducted studies to validate that gold is able to hedge against inflation (see Brown 1987; Harmston 1998; Ghosh et al. 2004; Ranson 2005; Levin and Wright 2006; Shahbaz et al., 2014; Bampinas and Panagiotidis, 2015; Van Hoang et al., 2016). Although the decisions on supporting or rejecting the hypothesis of gold's ability to hedge against inflation is theoretically and empirically inconclusive, the corresponding idea has helped originate the theory vastly. Due to inconclusiveness, the terminology of the theory will be greatly intriguing to be tested in this study to examine the assertion claimed by Malaysian economists. In addition, it is found that most studies are interested in testing the hypothesis in developed countries like those in Europe, (Harmston, 1998), the US (Greer, 2000), Japan (Wang and Lee, 2011), and those with new emerging economies like India (Levin and Wright, 2006).

This study uses the nonlinear model (instead of the linear model) to examine gold's hedging ability against inflation in Malaysia. It is essential to test the hypothesis in Malaysia because it has a different level of economic structure, therefore; unarguably requiring a concrete analysis to examine the differences. This study provides the benefits to both macro and micro levels of economics in Malaysia. At the macro level, policy makers could warn or suggest the public to hold gold if it proves its ability to hedge against the inflation rate. For example, if it is proven that gold can hedge against both, policymakers could launch a campaign suggesting that households and firms hold a few grams of gold per unit of economies. The significance for that reason is remarkable as this issue is related to the macroeconomic and microeconomic improvement through the 
management of inflation effects. At the micro level, individuals or households could diversify their portfolio in a good and safe way as gold, if proven, could hedge against inflation rate risk. The findings of this study will benefit those who are directly and indirectly involved in the decision making process, likely politicians, economists, policy makers, firms and households.

This study will mainly investigate the ability of gold to hedge against inflation in both short and long terms. Interestingly, to achieve the objectives, this study uses the EngleGranger (1987) and Johansen (1991) cointegration tests for a long term relationship. In order to investigate the hedging ability in short term, this study utilizes the nonlinear Threshold Vector Error Correction Model (TVECM) approach. Although there are various techniques to empirically analyze the objectives and estimate the models, this study was only limited to the proposed undertakings. Other techniques used in the recent literature are the autoregressive distributed lags (ARDL) model and innovative accounting approach (IAA) to examine the direction of causality by Shahbaz et al. (2014); timeinvariant and time varying cointegration framework by Bampinas and Panagiotidis (2015); the non-linear autoregressive distributed lags (ARDL) model used by Van Hoang et al (2016) and Markov-switching cointegration model by Aye et al. (2016). We use the TVECM method as our preferred estimation because it provides the system equation rather than single equation, and is able to evaluate the two-way causality effect.

The paper is organized as follows: Section 2 reviews the literature. Section 3 lays out the empirical model, estimation method and data. Section 4 contains a discussion of the empirical findings as well as the robustness checks. Section 5 provides a summary and conclusion.

\section{LITERATURE REVIEW}

This section reviews the empirical literature that supports the existence of cointegration between inflation and gold price regardless of the direction of the causality. Harmston (1998) investigates the French case and confirmed the positive correlation between gold prices and inflation. Adrangi et al. (2003) examines the connection between inflation and gold price by using the monthly gold price over the period from 1968 until 1999. Their empirical results indicate a positive correlation between the inflation rate and gold price. McCown and Zimmerman (2006) use the cointegration test to evaluate the long term correlation between gold price and inflation. The data comprised that the gold price in the US and US consumer price index, covering from 1970 until 2003. The findings indicate that there is a long term correlation between inflation and gold price.

Even though all the conclusions from literatures that have been discussed above show the existence of a correlation between the inflation rate and gold price, despite the direction of the relationship, this study should not ignore literatures that concluded the nonexistence of the cointegration between gold price and inflation. For example, Tully and Lucey (2007) conclude that the correlation between inflation and gold price was not significant. Laurent (1994) demonstrates that small deviations in inflation were not always reflected in the gold price. Blose (2010) examines the correlation between gold price and expected inflation. Using nonlinear regression on US monthly data from March 1988 to February 
2008, the empirical results indicate that the correlation between inflation and gold price is not significant.

Levin and Wright (2006) examine the determinants that affect the changes in the price of gold by using the vector error-correction model (VECM) and cointegration techniques from 1976 to 2005. They find that three main points were emerged: First, there is a long term correlation that exists between gold price and price level in the United States. Second, changes in the gold price and changes in the United States' inflation are positively correlated. Third, in the major gold consuming economies such as Saudi Arabia, China, Turkey, India and Indonesia, gold could be a reliable hedging tool against inflation.

Previous studies have shown in the long-run that inflation tends to appropriately increase the price of gold in the U.S., leading to gold's popularity as an asset in portfolios to reduce the risk against sudden inflation. However, gold is only partially effective in hedging against inflation in Japan. Wang et al. (2011) investigate the short-run and long-run inflation hedging effectiveness of gold in the United States and Japan during the period of January 1971 to January 2010. They find that the rigidity between the price of gold and the consumer price index affects the inflation hedging ability of gold in the long-run. The gold price is characterized by market disequilibrium induced by the price rigidity, causing the price of gold to be unable to response to changes in the CPI. To explore the inflation hedging ability of gold in the short-run, they further analyze the price rigidity in low and high momentum regime. It is found during the low momentum regimes that, gold return is unable to hedge against inflation in either the U.S. or Japan. However, during high momentum regimes, gold return is able to hedge against inflation in the U.S., while the price rigidity in Japan causes the price of gold to not fully hedge against inflation in the short-run.

In the case of Vietnam, Le Long et al. (2013) examine the inflation-hedging properties of gold reaching challenging records in 1980s-1990s. Consistent with conventional belief, they find that gold provides a complete hedge against both the ex post and ex ante inflation. Furthermore, its return is positively related to unexpected inflation, although the statistical evidence does not strongly support this. Nevertheless, in general, they cannot reject that gold does provide a complete hedge against inflation. In addition, their findings support the Fisher hypothesis that nominal gold returns move in a one-for-one correspondence with expected inflation.

Van Hoang et al. (2016) evaluate the role of gold as a hedge against inflation based on local monthly gold prices in China, India, Japan, France, the United Kingdom and the United States of America in periods during 1955 to 2015. They use the nonlinear autoregressive distributed lags (NARDL) model proposed by Shin et al. (2014). The main advantage of this model relies on its ability to simultaneously capture the short- and longrun asymmetries through positive and negative partial sum decompositions of changes in the independent variable(s). Their empirical results demonstrate that gold is not a hedge against inflation in the long run in all cases. In the short run, gold is an inflation hedge only in the UK, USA, and India. Moreover, there is no long-run equilibrium between gold prices and the CPI in China, India and France. This difference may be due to traditional aspects of gold and custom controls for gold trade in these countries. Further robustness check indicates that the data time-frequency does not change the specification of the 
NARDL model, but can change conclusions regarding the role of gold as a hedge against inflation in certain countries.

Arnold and Auer (2015) provide an overview of the state of scientific knowledge on inflation hedging. Specifically, they sanitize the empirical results of several decades of research analysing the relationship between maior asset classes, namely common stocks, gold, fixed income securities, real estate and inflation. Albeit previous studies have brought forth important facts characterising the interplay of asset returns and inflation rates (e.g., time-dependency, asymmetry, outlier-sensitivity and a tendency towards longterm but limited short-term inflation protection), there is still no consensus on the subject because sample, data and methodology issues preclude strict comparison of most studies. Therefore, they suggest that more research is required in this area from their review. They also outline possible directions for future research that may help to establish consensus among researchers.

\section{METHODOLOGY AND THE DATA}

The majority of the empirical econometric modeling work in economics assumes that relationships are linear. Recently, arguments have been presented, based on regularities observed in economic and financial data, that nonlinear specifications may be a more realistic representation during analysis of data. For example, in finance, stock returns tend to be more correlated when there is low volatility than when volatility is high. A similar behavior has been observed in exchange rate mechanisms where the exchange rate may be constrained to lie within a predetermined threshold level, according to Franses and van Dijk (2000). Taking dynamic behavior into account by using time series data, the Threshold autoregressive (TAR) model, introduced by Tong, Tong and Lim (1980) and extensively discussed in Tong (1990). The TAR model assumes that the regime is determined by a specified variable relative to a threshold value

The purpose of the TAR model is to verify whether gold is able to hedge against inflation in Malaysia in short term and to test the causality between those variables. To reach these goals, the model is specified as follows:

$\Delta g_{t}=f\left(i_{t}\right)$

where $i_{t}$ is the inflation rate, as the rate of inflation is captured by $i_{t}=\ln \left(\frac{c p i_{t}}{c p i_{t-1}}\right) X 100$; $g_{t}$ is the gold price in Malaysian ringgit $(\mathrm{RM}), \Delta g_{t}=\ln \left(\frac{g_{t}}{g_{t-1}}\right) X 100$ denotes the change rate of $g_{t}$. When $f^{\prime}>0$, gold return could cover the loss from the changes in the rising inflation rate.

Tong and Lim (1980) and Tong (1978) established the threshold autoregressive (TAR) model. They utilized the threshold value to split the short term dynamic state of an economic variable into two regimes. The threshold variable $Y_{t-d}$ decides the condition of the model in two regimes. 
$\Delta g_{t}=\left\{\begin{array}{l}i^{\prime}{ }_{t} \delta_{1}+\sum_{1}^{1 / 2} \varphi_{t} I F Y_{t-d}>\theta \\ i^{\prime}{ }_{t} \delta_{2}+\sum_{2}^{1 / 2} \varphi_{t} I F Y_{t-d} \leq \theta\end{array}\right.$

Equation (2) can be observed as two autonomous linear regressions if $\theta$ and $d$ are given. $\delta_{a}$ and $\Sigma$ are obtained as follows:

$\hat{\delta}_{a}(\theta, d)=\left(\sum_{t}^{(i)} i_{t} i^{\prime}{ }^{\prime}\right)^{-1}\left(\sum_{t}^{(i)} i_{t} g^{\prime}{ }_{t}\right), \sum_{a}(\theta, d)=\sum_{t}^{(a)}\left(g_{t}-i^{\prime}{ }_{t} \hat{\theta}_{a}^{*}\right)\left(g_{t}-i^{\prime}{ }_{t} \hat{\theta}_{a}^{*}\right)^{\prime} /\left(n_{a}-k\right)$

$k$ denotes the dimension of $i_{t}$ and $k<n . \theta_{a}^{*}=\hat{\delta}_{a}(\theta, d) n_{a}$ denotes the observations in regime 1 or 2 (which is represented by $a$. The residual sum of squares (RSS) for this model is as follows:

$S(\theta, d)=S_{1}(\theta, d)+S_{2}(\theta, d), S_{a}(\theta, d)=\operatorname{trace}\left[\left(n_{a}-k\right) \sum_{a}(\theta, d)\right]$

$\theta$ and $d$ can be obtained from Equation (3) as follows:

$\arg \min _{\theta, d} S(\theta, d), 1 \leq d \leq d_{0}$

and

$\theta \in R_{0}$

The best fit threshold model can be constructed after the optimal threshold value $(\theta)$ and the delay parameter $(d)$ has been obtained. According to Wang et. al (2011), disequilibrium adjustment of the prices and the gap of error correction term are capable of presenting high and low momentums, which might have different impacts on the inflation hedging ability of gold in the short run. Based on the results of the cointegration test, if the gold price in Malaysia is characterized by linear cointegration and the linearity test, showing short term nonlinearity between those two variables, this study will take the present threshold cointegration between gold return and inflation into consideration. Thus, this study constructs the TVECM to carry out the estimation. This model is as follows.

$\Delta g_{t}=\left\{\begin{array}{l}\alpha+\sum_{j=1}^{p} \alpha_{1,1 j} \Delta g_{t-j}+\sum_{j=1}^{p} \alpha_{1,2 j} i_{t-j}+\Gamma_{1} \mathrm{ECT}_{\mathrm{t}-1}+\varepsilon_{g 1 t}, \Delta \mathrm{ECT}_{\mathrm{t}-\mathrm{d}}>\theta \\ \alpha+\sum_{j=1}^{p} \alpha_{2,1 j} \Delta g_{t-j}+\sum_{j=1}^{p} \alpha_{2,2 j} i_{t-j}+\Gamma_{2} \mathrm{ECT}_{\mathrm{t}-1}+\varepsilon_{g 2 t}, \Delta \mathrm{ECT}_{\mathrm{t}-\mathrm{d}} \leq \theta\end{array}\right.$

$\mathrm{i}_{\mathrm{t}}=\left\{\begin{array}{l}\beta+\sum_{\mathrm{j}=1}^{\mathrm{p}} \beta_{1, \mathrm{lj}} \Delta \mathrm{g}_{\mathrm{t}-\mathrm{j}}+\sum_{\mathrm{j}=1}^{\mathrm{p}} \beta_{1,2 \mathrm{j}} \mathrm{i}_{\mathrm{t}-\mathrm{j}}+\Gamma_{3} \mathrm{ECT}_{\mathrm{t}-1}+\varepsilon_{\mathrm{g} 1 \mathrm{t}}, \Delta \mathrm{ECT}_{\mathrm{t}-\mathrm{d}}>\theta \\ \beta+\sum_{\mathrm{j}=1}^{\mathrm{p}} \beta_{2, \mathrm{lj}} \Delta \mathrm{g}_{\mathrm{t}-\mathrm{j}}+\sum_{\mathrm{j}=1}^{\mathrm{p}} \beta_{2,2 \mathrm{j}} \mathrm{i}_{\mathrm{t}-\mathrm{j}}+\Gamma_{4} \mathrm{ECT}_{\mathrm{t}-1}+\varepsilon_{\mathrm{g} 2 \mathrm{t}}, \Delta \mathrm{ECT}_{\mathrm{t}-\mathrm{d}} \leq \theta\end{array}\right.$

Momentum between both prices is presented by the differential of error correction term of lag d, $\Delta \mathrm{ECT}_{\mathrm{t}-\mathrm{d}}$ is applied to be the threshold variable, where $\mathrm{ECT}_{\mathrm{t}-1}=\Delta g_{t}-\hat{\alpha}-$ 
$\hat{\beta} c_{t} . \Delta \mathrm{ECT}_{\mathrm{t}-\mathrm{d}}>\theta$ signifies regime 1: adjustment momentum between gold price and consumer price is faster (high momentum period). $\Delta \mathrm{ECT}_{\mathrm{t}-\mathrm{d}} \leq \theta$ signifies regime 2 : adjustment momentum between gold price and consumer price is slower (low momentum period). This threshold variable utilizes momentum to estimate the error correction model. The differential of error correction term, or the disequilibrium adjustment of prices, is able to present high and low momentums, which might have different effects on the inflation hedging ability of gold in the short-run.

$\Gamma_{1}$ and $\Gamma_{2}$ in Equation (5) denote the short term error correction model of gold return. $\Gamma_{1}$ and $\Gamma_{2}$ in Equation (6) denote the short term error correction model of inflation.

\subsection{Asymmetric Causality Test}

Using the TVECM that has been developed, this study can now test the hedging ability and causality between variables. This study will utilize the Wald Coefficient Test based on Equations (5) and (6) to obtain the sum of coefficients and to check the level of significance for each coefficient. The Wald test is used to test the joint significance of a subset of coefficients. Significance positive sum of coefficient:

$$
\sum_{j=1}^{p} \alpha_{1,2 j}
$$

for inflation rate when gold return is the dependent variable shows that inflation rate does cause changes in gold return in the same direction. This is proof for the hedging ability of gold against inflation. Similarly, when inflation rate is the dependent variable, if the sum of coefficients for gold return:

$$
\sum_{j=1}^{p} \alpha_{2,2 j}
$$

is significantly positive, it shows that gold return does cause changes in inflation rate in the same direction.

The sum of coefficients of ECT in Equation (5) signifies the adjustment speed of error correction term in regime 1 and regime 2 . If the coefficient of adjustment speed is positive, it means that gold return and long term equilibrium error are facing the positive adjustment. The sum of coefficients of ECT in Equation (6) signifies the adjustment speed of error correction term in regime 1 and regime 2. If the coefficient of adjustment speed is positive, it means that inflation and long term equilibrium error are facing the positive adjustment.

Wang et. al. (2011), as the main reference in this study, found that gold can be hedged against inflation during the high momentum of inflation and should not invest in gold during low momentums of inflation as gold is incapable in hedging against inflation. This gives us the expectation that gold could only be able to hedge against inflation during high momentums of inflation regime. This finding referred to the positive value of the sum of 
coefficients of the inflation when gold return is the dependent variable and the result is significant.

Finally, to conclude the ability of short term hedging of gold against inflation in Malaysia, this study concentrates on the results of the sums of coefficients to be positive. If the sum of coefficients follows the restrictions of validating the hypothesis, then the hedging ability of gold against inflation in Malaysia can be affirmative.

\section{THE DATA}

This study uses the gold price per ounce in RM based on the London PM Fix on a monthly data basis. The data of gold price comes from the World Gold Council Value Research \& Statistics Database. The rate of inflation was obtained from the International Financial statistics, IMF on a monthly basis. This study covers from January 1971 to September 2011, totaling at 501 observations. The year 1971 was picked as it was the year when the Bretton Wood system collapsed and the convertibility of the currency to gold was terminated. Harmston (1998) proves that the price of gold and its purchasing power significantly increased after the demolision of the Bretton Wood system in 1971.

\subsection{Empirical Results and Discussions}

Table 1 reports the unit root tests, where the results of gold price and CPI are integrated of I (1). This implies that these two series are stationary after they were being differenced in first order. Referring to Table 1, these two variables are stationary in the first difference, where the null hypothesis of unit root is rejected at $1 \%$ significance level after being first difference.

Table 1: Results of Unit Root Tests

\begin{tabular}{ccccc}
\hline \hline & \multicolumn{2}{c}{ ADF } & \multicolumn{2}{c}{ Phillip-Perron } \\
\cline { 2 - 5 } & Intercept & Intercept and trend & Intercept & Intercept and trend \\
\hline \multirow{5}{c}{ Level } \\
Gold Price & 5.418 & 4.155 & 5.602 & 4.338 \\
CPI & 0.744 & -2.278 & 1.019 & -2.083 \\
\hline \multirow{5}{c}{ Gold Price } & $-15.613^{* * *}$ & $-16.189^{* * *}$ & $-18.910^{* * *}$ & $-19.228^{* * * *}$ \\
CPI & $-16.347^{* * *}$ & $-16.371^{* * *}$ & $-16.222^{* * *}$ & $-16.227^{* * *}$ \\
\hline \hline
\end{tabular}

Notes: The table shows the t-statistic of the respective unit root test. *,** and *** denote significant at $10 \%$, $5 \%$ and $1 \%$ levels, respectively.

After determining the stationarity of the variables, the long term cointegration tests are implemented. Table 2 reports the results of the Engle-Granger cointegration test and the long term estimation of the coefficients for a full sample period. The estimation was based on a long term model shown in Equation (5). The test result reveals that there is a long term relationship between CPI and gold price in Malaysia. The ADF statistic value shows insignificant at conventional level, hence it can be concluded that the cointegration between these two variables exists. The ability of gold to act as a hedge against inflation 
in the long run can be determined with the cointegration parameter, namely the $\beta$ coefficient. The value of $\beta$ in Table 2 points out that when Malaysian CPI rises by $1 \%$, gold price in Malaysia will increase by $1.7615 \%$, indicating that gold can fully hedge against inflation. Error correction terms from this regression will be used in the TVECM analysis for the short term.

To further validate the existence of the cointegration between gold price and CPI in Malaysia, this study proceeds with the Johansen cointegration test. Table 3 presents the results of the Johansen Cointegration test between CPI and price of gold which reports the Trace statistics and the Maximum Eigenvalue. Based on these two statistic results, this study found existence of the long term cointegration between gold price and CPI in Malaysia. This finding can validate the result from the Enger Granger Cointegration test as reported in Table 2.

Table 2: Result of the Engle-Granger Bivariate Cointegration Test

\begin{tabular}{cc}
\hline \hline Parameters & Test Statistics \\
\hline$\alpha$ & $-0.5426(0.0000)$ \\
$\beta$ & $1.7615(0.0000)^{* * *}$ \\
ADF Statistic & $-2.3977[4]$ \\
\hline \hline
\end{tabular}

Notes: The maximum lag used is 17 periods. Optimal lag selection is chosen based on AIC. The values in brackets are p-values. Value in parentheses is optimum lag selection. $* *$ and $* * *$ denote significant at $5 \%$ and $1 \%$ levels, respectively.

Table 3: Results of the Johansen Cointegration Test

\begin{tabular}{|c|c|c|c|c|c|c|c|}
\hline $\begin{array}{c}\text { Number of } \\
\text { cointegration }\end{array}$ & Eigenvalue & $\begin{array}{c}\text { Trace } \\
\text { Statistic }\end{array}$ & $\begin{array}{c}5 \% \text { Critical } \\
\text { Value }\end{array}$ & $P$-value & $\begin{array}{c}\text { Max Eigen } \\
\text { Statistic }\end{array}$ & $\begin{array}{c}0.05 \text { Critical } \\
\text { Value }\end{array}$ & P-value \\
\hline None & 0.0222 & 13.5786 & 15.4947 & $0.0352^{* * *}$ & 11.1548 & 14.2646 & $0.0466 * *$ \\
\hline At most 1 & 0.0048 & 2.4238 & 3.8414 & 0.6822 & 2.4238 & 3.8414 & 0.1195 \\
\hline
\end{tabular}

Note: $*, * *$ and $* * *$ denote significant at $10 \%, 5 \%$ and $1 \%$ levels, respectively.

In this study, the Tsay's linearity test is required to find the optimum lag of the VAR model with the aim to test the hypothesis of linearity. This study uses several criteria in selecting the optimal VAR lag length and the results are reported in Table 4. The optimal lag order is 6 lags since 3 out of 6 criteria indicate significance at 5\%. Therefore, lag 6 is utilized based on the Tsay (1998) linearity test.

Table 4: The VAR Lag Selection

\begin{tabular}{|c|c|c|c|c|c|c|}
\hline $\bar{L} \operatorname{Lags}(p)$ & $\bar{L} \log L$ & 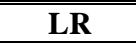 & (AIC & 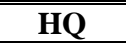 & FPE & $\overline{\mathrm{SC}}$ \\
\hline 1 & -1815.688 & 93.262 & 7.394 & 7.410 & 5.553 & $7.446 * *$ \\
\hline 2 & -1808.269 & 14.687 & 7.376 & $7.409 * *$ & 5.477 & 7.467 \\
\hline 3 & -1801.375 & 13.591 & 7.3646 & 7.411 & 5.413 & 7.483 \\
\hline 4 & -1797.432 & 7.7411 & 7.3648 & 7.425 & 5.414 & 7.518 \\
\hline 5 & -1795.420 & 3.9351 & 7.3721 & 7.449 & 5.458 & 7.560 \\
\hline 6 & -1788.453 & $13.566 * *$ & $7.3608 * *$ & 7.447 & $5.391 * *$ & 7.582 \\
\hline 7 & -1784.714 & 7.250 & 7.3619 & 7.465 & 5.395 & 7.617 \\
\hline 8 & -1780.472 & 8.191 & 7.362 & 7.474 & 5.393 & 7.656 \\
\hline
\end{tabular}

Notes: AIC denotes Akaike information criterion; HQ denotes Hannan Quinn information criterion; FPE denotes final prediction error and SC denotes Schwarz information criterion. ** denotes significant at 5\% level. 
It is found that when VAR lag is 6, the null hypothesis of linearity is rejected when the delay parameter (chosen based on the biggest delay parameter before insignificant) is 3 . It is found that the correlation between gold return and inflation rate in short term is a nonlinear relationship. The test result is reported in Table 5.

Table 5: Tsay's Linearity Test (Full Sample Period: 1971-2011)

\begin{tabular}{ccccccc}
\hline \hline $\boldsymbol{d} \boldsymbol{p}$ & $\mathbf{1}$ & $\mathbf{2}$ & $\mathbf{3}$ & $\mathbf{4}$ & $\mathbf{5}$ & $\mathbf{6}$ \\
\hline 1 & 0.6807 & 0.5757 & 0.0863 & 0.0036 & 0.0004 & 0.0019 \\
2 & & 0.5273 & 0.4035 & 0.1225 & 0.0093 & 0.0097 \\
3 & & & 0.0910 & 0.0045 & 0.0019 & $\mathbf{0 . 0 0 0 9 * * *}$ \\
4 & & & & 0.0105 & 0.0028 & 0.0220 \\
5 & & & & 0.0021 & 0.0032 \\
6 & & & & & & 0.2527 \\
\hline \hline
\end{tabular}

Notes: The values indicate the chi-square value in the Tsay Linearity test. $p$ denotes lags of VAR and $d$ denotes delay parameter. $*, * *$ and $* * *$ denote significant at $10 \%, 5 \%$ and $1 \%$ levels, respectively.

After obtaining the delay parameter (which is 3 ) from the linearity test, this study can now use TVECM analysis to determine the level of threshold for the inflation. The threshold level that has been determined falls at -0.0244 for the full sample period as calculated in $\mathrm{R}$ software. After dividing the momentum or the ECT based on the threshold level, 63\% of the data set falls into the first regime where momentum is higher than the threshold level and the rest falls in the second regime. Based on the threshold value that has been obtained and the TVECM model that has been developed, this study proceeds with asymmetric causality test where the Wald coefficient test is used. Firstly, the lag length for the causality test should be determined and the results are presented in Table 6 . The lag determination is based on AIC and the number of lag that has been chosen for all estimations, bolded in Table 6 .

Table 6: Lag Length Selection for Causality Test

\begin{tabular}{ccccc}
\hline \hline $\begin{array}{c}\text { Dependent } \\
\text { Variable }\end{array}$ & \multicolumn{2}{c}{$\Delta$ of gold price } & \multicolumn{2}{c}{ Inflation rate } \\
\hline Lag & $\begin{array}{c}\text { High } \\
\text { Momentum } \\
\text { Regime }\end{array}$ & $\begin{array}{c}\text { Low } \\
\text { Momentum } \\
\text { Regime }\end{array}$ & $\begin{array}{c}\text { High } \\
\text { Momentum } \\
\text { Regime }\end{array}$ & $\begin{array}{c}\text { Low } \\
\text { Momentum } \\
\text { Regime }\end{array}$ \\
\hline 1 & -12.75778 & -12.02444 & -11.97759 & -12.73053 \\
2 & -12.79117 & $\mathbf{- 1 2 . 1 0 6 4 4}$ & $\mathbf{- 1 1 . 9 9 8 6 3}$ & $\mathbf{- 1 2 . 7 3 0 7 8}$ \\
3 & $\mathbf{- 1 2 . 8 0 9 7 7}$ & -12.09933 & -11.90581 & -12.71560 \\
4 & -12.80715 & -12.10622 & -11.86185 & -12.63124 \\
\hline
\end{tabular}

Note: The values are based on the AIC criterion to determine the best lag for estimation.

Table 7 presents the outcome of the Wald coefficient test. The result indicates that there is a strong exogenity and positive value of sum of coefficients of inflation rate (1.7481 in high momentum regime and 0.6562 in low momentum regime) in both regimes when the dependent variable is gold return. This finding indicates that the null hypothesis can be rejected and confirms that the inflation rate has a positive impact on gold return in the short run. This also reveals that that gold is able to act as an effective hedging tool against inflation rate fluctuation in both regimes. This finding is in line with Worthington and 
Pahlavani (2006), Dempster and Artigas (2010) and Faugere and Van Erlach (2005), who also found the same conclusion that gold could be an effective hedging tool against inflation. Table 8 reports the diagnostic tests of the model and all tests demonstrate that the empirical results are satisfactory and the models are well-specified.

Table 7: The Wald Coefficient Test Results for TVECM Model

\begin{tabular}{|c|c|c|c|c|c|}
\hline $\begin{array}{c}\text { Dependent } \\
\text { Variable }\end{array}$ & $\begin{array}{c}\text { Null } \\
\text { hypothesis }\end{array}$ & \multicolumn{2}{|c|}{ High Momentum Regime } & \multicolumn{2}{|c|}{ Low Momentum Regime } \\
\hline \multicolumn{2}{|c|}{ Threshold Level } & \multicolumn{2}{|c|}{$>-0.0244$} & \multicolumn{2}{|c|}{$<-0.0244$} \\
\hline & & $\begin{array}{c}\text { Sum of } \\
\text { coefficients }\end{array}$ & $\begin{array}{c}\text { Chi-square } \\
\text { test }\end{array}$ & $\begin{array}{c}\text { Sum of } \\
\text { coefficients }\end{array}$ & $\begin{array}{c}\text { Chi-square } \\
\text { test }\end{array}$ \\
\hline \multirow[t]{2}{*}{$\begin{array}{l}\text { Gold } \\
\text { return }\end{array}$} & $\begin{array}{l}\text { Inflation rate } \\
\text { does not affect } \\
\text { gold return }\end{array}$ & $\sum_{j=1}^{p} \alpha_{1,2 j}=1.7481$ & $17.4352 * *$ & $\sum_{j=1}^{p} \alpha_{2,2 j}=0.656$ & $16.5638 *$ \\
\hline & $\begin{array}{l}\text { ECT does not } \\
\text { affect gold } \\
\text { return }\end{array}$ & $\Gamma_{1}=-0.0136$ & 1.7473 & $\Gamma_{2}=-0.0271$ & 0.8452 \\
\hline \multirow[t]{2}{*}{$\begin{array}{l}\text { Inflation } \\
\text { rate }\end{array}$} & $\begin{array}{l}\text { Gold return } \\
\text { does not affect } \\
\text { inflation rate }\end{array}$ & $\sum_{\mathrm{j}=1}^{\mathrm{p}} \beta_{1, \mathrm{lj}}=0.1057$ & 1.3913 & $\sum_{\mathrm{j}=1}^{\mathrm{p}} \beta_{2,1 \mathrm{j}}=0.008$ & 3.204 \\
\hline & $\begin{array}{l}\text { ECT does not } \\
\text { affect inflation } \\
\text { rate }\end{array}$ & $\Gamma_{3}=0.0012$ & 0.9368 & $\Gamma_{4}=0.0037$ & 0.7389 \\
\hline
\end{tabular}

Notes: The threshold value is determined at -0.0244 ; The TVECM model's lag length $(p)=6$ and delay parameter $(\mathrm{d})=3 . *, * *$ and $* * *$ denote significant at $10 \%, 5 \%$ and $1 \%$ levels, respectively.

Table 8: Diagnostic Tests

\begin{tabular}{|c|c|c|c|c|c|c|}
\hline \multirow[t]{3}{*}{$\begin{array}{c}\text { Dependent } \\
\text { Variable } \\
\end{array}$} & \multicolumn{3}{|c|}{ High Momentum Regime } & \multicolumn{3}{|c|}{ Low Momentum Regime } \\
\hline & & $>-0.0244$ & & & $<-0.0244$ & \\
\hline & LM test & $\begin{array}{c}\text { Ramsey } \\
\text { Reset test }\end{array}$ & $\begin{array}{c}\text { Cusum } \\
\text { Test }\end{array}$ & LM test & $\begin{array}{c}\text { Ramsey } \\
\text { Reset test }\end{array}$ & $\begin{array}{c}\text { Cusum } \\
\text { test }\end{array}$ \\
\hline \multicolumn{7}{|c|}{ Full Sample Period (1971-2011) } \\
\hline \multirow[t]{2}{*}{ Gold Return } & 0.6851 & $(2.8031)$ & Stable & 2.9231 & $(1.3071)$ & \multirow{2}{*}{ Stable } \\
\hline & [0.0192] & {$[0.2607]$} & & [0.0982] & {$[0.3461]$} & \\
\hline \multirow{2}{*}{ Inflation rate } & 1.9951 & $(0.5821)$ & Stable & 1.7048 & $(0.3826)$ & \multirow{2}{*}{ Stable } \\
\hline & [0.0271] & [0.4458] & & [0.0487] & [0.6935] & \\
\hline \multicolumn{7}{|c|}{ Sub Sample Period (2000-2011) } \\
\hline \multirow[t]{2}{*}{$\Delta$ of gold price } & $(7.1452)$ & $(0.0572)$ & Stable & $(4.5894)$ & $(0.2404)$ & \multirow{2}{*}{ Stable } \\
\hline & {$[0.0281]$} & [0.8112] & & [0.0938] & {$[0.6247]$} & \\
\hline \multirow[t]{2}{*}{ Inflation rate } & $(7.4273)$ & $(0.3712)$ & Stable & $(8.0706)$ & $(0.6302)$ & \multirow{2}{*}{ Stable } \\
\hline & [0.0344] & [0.5434] & & [0.0177] & [0.4287] & \\
\hline
\end{tabular}

Note: $\mathrm{t}$-value in the parentheses (...) and p-value for diagnostic test in parentheses [...] 


\section{IMPULSE RESPONSE ANALYSIS}

To further explore the inflation hedging effectiveness of gold and its effecting period of hedge, the impulse response analysis is applied for both high and low momentum regimes. Figures 1,2, 3 and 4 show the results of impulse response analysis for the full sample period. Figures 1 and 3 depict the response of inflation to gold return in regimes 1 and 2, respectively. Figures 2 and 4 depict the response of gold return to inflation in regime 1 and regime 2, respectively. During the high momentum regime in a full sample period, the significant positive response of inflation rate to gold return are in periods 2,9 and 10 . During the low momentum regime in the full sample period, the impulse responses of inflation rate to gold return are positively significant in periods 3 and 8 only.

Figure 1: The Impulse Response to Cholesky one S.D. innovations \pm 2 S.E of Inflation Rate to Gold Return in High Momentum regime (Full Sample Period)

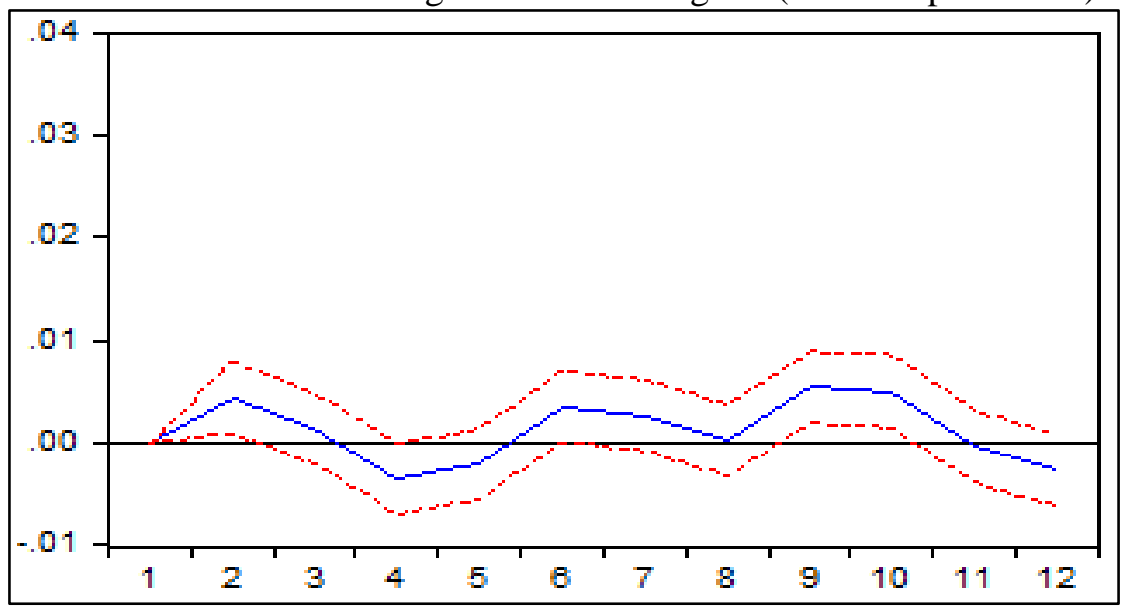

Figure 2: The Impulse Response to Cholesky one S.D. innovations \pm 2 S.E of Gold Return to Inflation rate in High Momentum Regime (Full Sample Period)

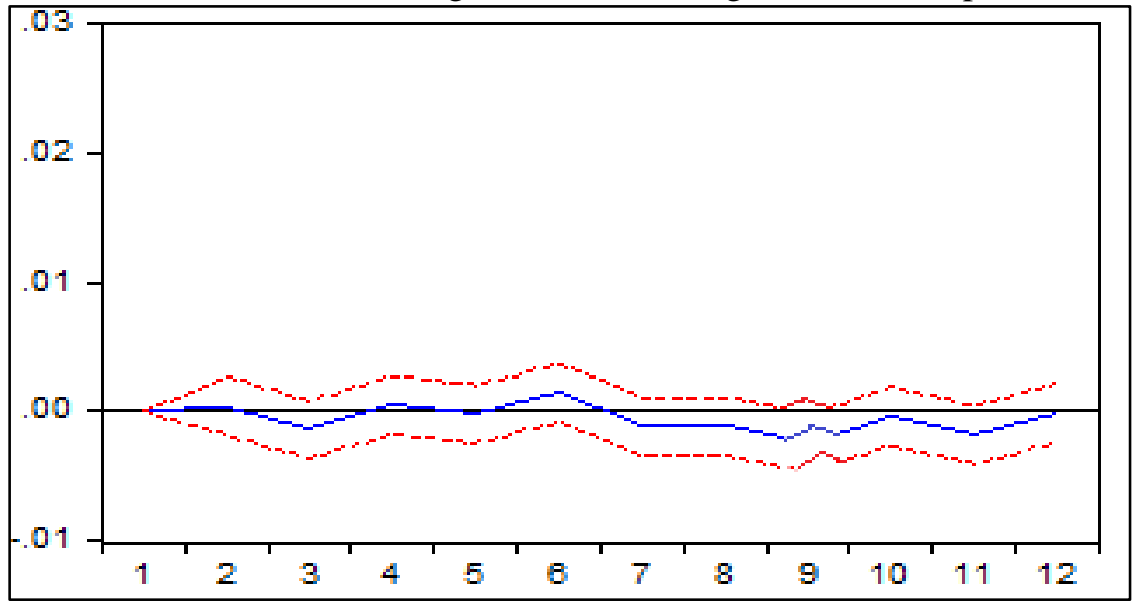


Figure 3: The Impulse Response to Cholesky one S.D. innovations \pm 2 S.E of Inflation Rate to Gold Return in Low Momentum regime (Full Sample Period)

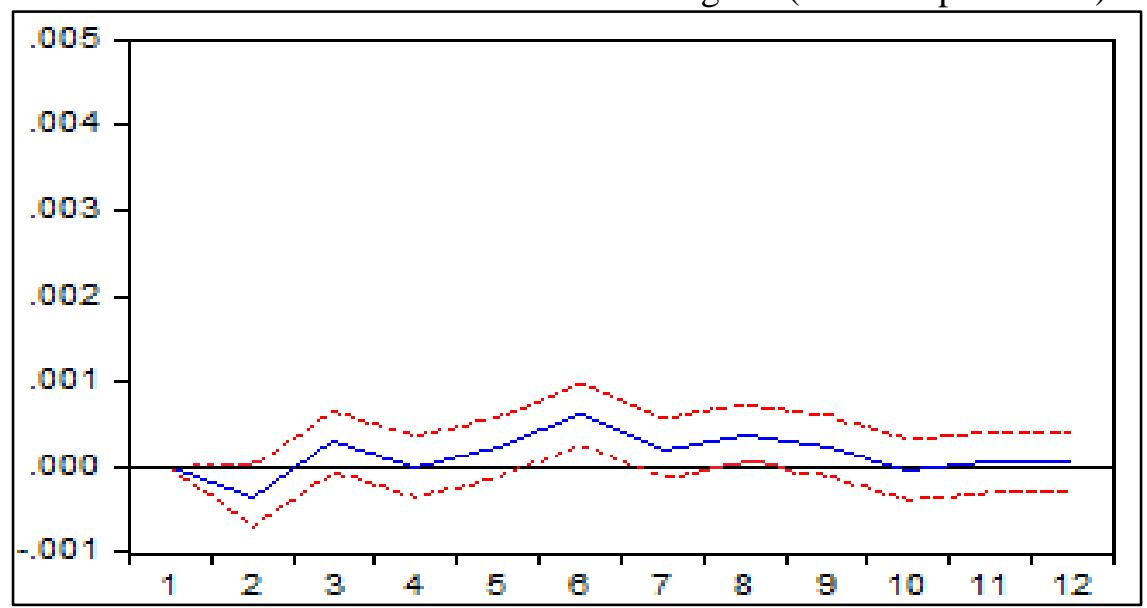

Figure 4: The Impulse Response to Cholesky one S.D. innovations \pm 2 S.E of Gold Return to Inflation rate in Low Momentum Regime (Full Sample Period)

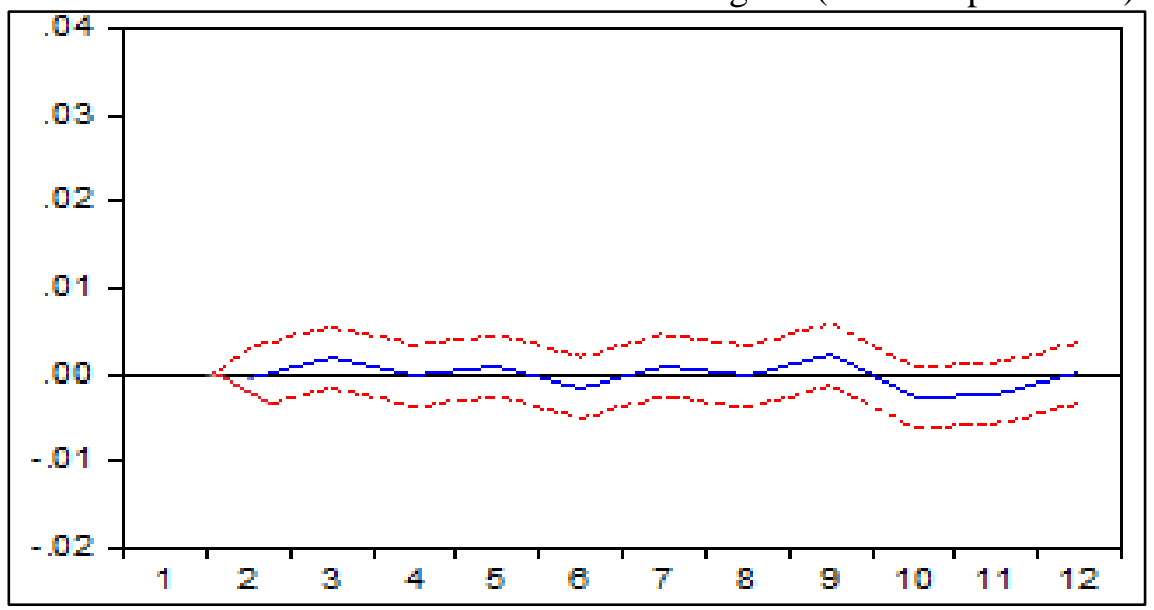

The impulse response results show that the inflation hedging of gold is effective during both high and low momentum regimes. These findings are able to prove the inflation hedge effectiveness of gold in both regimes. These results from impulse response analysis are in line with the findings from the asymmetrical TVECM for short term analysis that has been employed earlier. 


\section{CONCLUSION}

This study examines whether gold can be used as a hedging tool against inflation in Malaysia by using time series analysis. The empirical findings show that the gold's hedging ability in long term is proven through the results from the Engle-Granger cointegration test and also the existence of the long-term Johansen cointegration test. Then, the Tsay's linearity test was used and the results demonstated that the correlation between gold and inflation is nonlinear in the short run, thus, the finding allowed us to proceed with the nonlinear TVECM model in the short term analysis. In addition to that, the results also showed that during high momentum regimes, the hedging ability of gold against inflation is higher as compared to regimes where the momentum is lower than the threshold level.

From the empirical results, this study concludes that gold can act as an effective hedging tool against inflation in Malaysia. This would imply that holding gold by various entities in Malaysia could manage the risks and effects of inflation and hence, it is efficient to facilitate the economy performance. If a person could manage the effects of inflation right, then the standard of living could be better off while enjoying the positive effects of inflation, for example, economic growth. Investors should diversify investment or saving portfolios and add gold to them. The same goes to firms as they could also add gold savings into their portfolio to hedge against the effect from the inflation.

The positive causal relationship between the Malaysian inflation rate and gold return when gold is a dependent variable shows that the increasing inflation rate causes positive changes in gold price. This could be a good signal for households, investors, firms, or the government. When facing the rising inflation, people could expect the price of gold to be higher next. Therefore, a good intuition should tell them to buy gold at that time to enjoy higher gold return and at the same time, hedging the effect of inflation. As the developing countries commonly face increasing price levels, people could predict the continuous rise in the price of gold. However, people or firms that buy gold must take considerable action to diversify with other investments or savings while pursuing this goal.

Since this is a relatively new study in terms of its area of research in Malaysia, there are certain obstacles which can be seen as limitations to this study. The lack of studies regarding gold as a hedge against inflation in Malaysia leads to lacking of literature. Gold investing on the Malaysian market is a fairly new investment portfolio. Literature studying the same issue also used different sets of methodology and can be considered that almost no literatures use the same as the others.

\section{REFERRENCES}

Adrangi, B., Chatrath, A., \& Raffiee, K. (2003). Economic Activity, Inflation and Hedging: The Case of Gold and Silver Investments. The Journal of Wealth Management, 6(2), 60-77.

Arnold, S., \& Auer, B. R. (2015). What do scientists know about inflation hedging? The North American Journal of Economics and Finance, 34, 187-214. 
Artigas, J. C. (2010), Linking Global Money Supply to Gold and to Future Inflation, London: World Gold Council.

Aye, G. C., Chang, T., \& Gupta, R. (2016). Is gold an inflation-hedge? Evidence from an interrupted Markov-switching cointegration model. Resources Policy, 48, 77-84.

Bampinas, G., \& Panagiotidis, T. (2015). Are gold and silver a hedge against inflation? A two century perspective. International Review of Financial Analysis, 41, pp. 267-276.

Blose, L. E. (2010). Gold prices, cost of carry, and expected inflation. Journal of Economics and Business, 62(1), 35-47.

Bodie, Z. (1976). Common Stocks as a Hedge Against Inflation. Journal of Finance, 31, $459-470$.

Bodie, Z. (1979). Hedging against inflation. Sloan Management Review, 21, 15 - 24.

Brown, K. C. (1987). On the Use of Gold as a Fixed Income Security. Financial Analysts Journal, 43(4), 73-79.

Dempster, N., \& Artigas, J. (2010). "Gold: Inflation Hedge and Long-Term Strategic Asset. Journal of Wealth Management, 13(2), 69-75.

Engle, R. F., \& Granger, C. W. J. (1987). Co-Integration and Error-Correction: Representation, Estimation and Testing. Econometrica, 55(2), 251-276.

Faugere, C., \& Van Erlach, J. (2005). The Price of Gold: A Global Required Yield Theory. The Journal of Investing, 14, 99-111.

Franses, P. H., \& van Dijk, D. (2000). Non-linear Time Series Models in Empirical Economics. UK: Cambridge University Press.

Ghosh, D. P., Levin, E. J., Macmillan, P., \& Wright, R. E. (2004). Gold as an Inflation Hedge? Studies in Economics and Finance, 22(1), 1-25.

Greer, R. J. (2000). The Nature of Commodity Index Returns. Journal of Alternative Investments, 3(2), 45-52.

Harmston, S. (1998). Gold as a Store of Value. London: Centre for Public Policy Studies, The World Gold Council.

Johansen, S. (1991). Estimation and Hypothesis Testing of Cointegration Vectors in Gaussian Vector Autoregressive Models. Econometrica, 59(6), 1551-1580.

Laurent, R. D. (1994). Is There a Role for Gold in Monetary Policy? Economic Perspectives, 18(2), 2-14.

Le Long, H., de Ceuster, M. J. K., Annaert, J., \& Amonhaemanon, D. (2013). Gold as a Hedge against Inflation: The Vietnamese Case. Procedia Economics and Finance, 5, 502-511.

Levin, E. R., \& Wright, R. E. (2006). Short-Run and Long-Run Determinants of the Price of Gold. London: World Gold Council.

McCown, J. R., \& Zimmerman J. R. (2006). Is Gold a Zero-Beta Asset? Analysis of the Investment Potential of Precious Metals. Oklahoma City University Working Paper Series.

Ranson, D., \& Wainright, H. C. (2005). Why gold, Not Oil, Is the Superior Predictor of Inflation. London: World Gold Council.

Shahbaz, M., Tahir, M. I., Ali, I., \& Rehman, I. U. (2014). Is gold investment a hedge against inflation in Pakistan? A co-integration and causality analysis in the presence of structural breaks. The North American Journal of Economics and Finance, 28, 190-205.

Shin, Y., Yu, B., \& Greenwood-Nimmo, M. (2014). Modelling asymmetric cointegration and dynamic multipliers in a nonlinear ARDL framework. In R. C. Sickles \& W. C. Horrace (Eds.), Festschrift in Honor of Peter Schmidt: Econometric Methods and Applications (pp. 281-314). New York: Springer. 
Tong, H. (1978). On a Threshold Model. In C. H. Chen (Eds.), Pattern Recognition and Signal Processing (pp. 101-141). Amsterdam: Siithoff \& Noordhoff.

Tong, H. (1990). Non-linear time series: a dynamical system approach. UK: Oxford University Press.

Tong, H., \& Lim, K. S. (1980). Threshold autoregression, limit cycles and cyclical data. Journal of the Royal Statistical Society: Series B: Methodological, 42(3), 245-292.

Tsay, R. S. (1998). Testing and Modeling Multivariate Threshold Models. Journal of the American Statistical Association, 93(443), 1188-1202.

Tully, E., \& Lucey B. M. (2007). A Power GARCH Examination of the Gold Market. Research in International Business and Finance, 21(2), 316-325.

van Hoang, T. H., Lahiani, A., \& Heller, D. (2016). Is gold a hedge against inflation? New evidence from a nonlinear ARDL approach. Economic Modelling, 54, 54-66.

Wang, K. M., \& Lee Y. M. (2011). The Yen for Gold. Resources Policy, 36(1), 39-48.

Wang, K. M., Lee Y. M., \& Nguyen Thi, T. B. (2011). Time and Place Where Gold Acts as an Inflation Hedge: An Application of Long-Run and Short-Run Threshold Model. Economic Modelling, 28(3), 806-819.

Worthington, A. C., \& Pahlavani, M. (2006). Gold Investment as an Inflation Hedge: Cointegration Evidence with Allowance for Endogenous Structural Breaks. University of Wollongong, Accounting \& Finance Working Paper 06/04. 